\title{
The representations of the regional university students about the "gap year" in conditions of the Covid-19 pandemic
}

\author{
Sergei Kremen, and Kseniya Tsitsika shvili* \\ Smolensk State University, Przhevalsky str., 4, 214000 Smolensk, Russia
}

\begin{abstract}
The article examines the phenomena of the "gap year" in the conditions of the COVID-19 pandemic. The purpose of this study is to analyze the regional university students' perceptions of this phenomenon in general and in the context of the pandemic, in particular. The results of the study showed that many students have only a superficial understanding of the "gap year" and most would not want to take a year of gap in education for a number of reasons. The authors conclude that in the Russian reality it is quite difficult to implement the "gap year" due to the low level of awareness about it among schoolchildren and students, weak financial and mobile opportunities for the majority of Russians, and conservative views of most parents.
\end{abstract}

\section{Introduction}

The modern world is characterized by ever-evolving challenges. The COVID-19 pandemic has brought significant changes to all spheres of life, including education: classes have been transferred to a remote format, the time for passing the Unified State Exam was changed, and the admission campaign to universities has been postponed and simplified [1].

Unpredictable changes in the labor market, the deterioration of the material well-being of many families, the fear for the health of themselves and their loved ones caused by quarantine, have led to the fact that one of the most important steps in a person's life - the choice of profession, became an even more difficult test for school graduates and their parents. In this connection, prospective applicants were faced with a serious question: should they apply to university in 2020 at all, or should they postpone their applications to next year, hoping that the situation will change for the better?

In contrast to graduates of metropolitan cities and regions with large university centers, opportunities for graduates from the provinces are much lower, primarily in financialterms. According to research data, in 2020 there was not only a decrease in the migration activity of school graduates, but also a decrease in the demand for large university centers [2]. And if in developed countries more than usually young people have decided to postpone admission to an educational institution, take a "gap year", that is, a break of no more than two years between the moment of graduation from school and admission to university [3]

\footnotetext{
*Corresponding author: xeniats@yandex.ru
} 
or any break from study for the purpose of subsequent self-development [4], in Russia, th is is still quite a rare phenomenon.

\subsection{Literature review}

The "gap year" phenomenon is quite well studied abroad. The tradition of gap year education between school and university appeared in the middle of the 20th century in Great Britain [4-6] and was largely connected with the desire of young people to be independent of their parents. After finishing school young people traveled, gained experience, earned money for future studies at university, mastered additional skills, and participated in various charity and volunteer programs [3, 7]. Large associations have emerged around this phenomenon. For example, to develop special programs and conduct experiments in shaping future careers "Gap Year Association" was created in the USA [8].

A gap year has its advantages and disadvantages. On the one hand, such a break is necessary to recuperate after a difficult graduation class and state tests and is an opportunity to prepare for a more successful retake of examinations. In addition, a young person, not being in a continuous race "school-exams-university", can seriously consider his professional choice; objectively correlate his desires with opportunities: gaining work experience, participation in volunteer programs, and even travel. All of this is extremely helpful for young people to get used to their new "adult" status, to find themselves.

However, the "gap year" has its disadvantages. For many people the sign of success is to go to university immediately after school, the postponement of this moment seems something wrong, an indicator that the graduate did not pass the exams well and could not get in. A young person is faced with misunderstandings, if not by parents, then teachers, friends, peers; in a year, he may lose the desire to study. Another difficulty is the material component: not all parents are ready to pay for their child to stay abroad or in another city, and the question of how quickly a teenager will get an education and start earning is crucia 1 [9]. In our country, these problems are compounded by compulsory military service for young men.

Foreign studies have shown a variety of reasons for missing a whole year before admission. Birch and Miller noted that most Australian applicants took a "gap year" and more than half of them spent the free time they had on job hunting or preparing to enter a university, trying to improve their exam results, with only about $6 \%$ of those surveyed spending the yearon travel [10].

Participation in volunteer programs and internships helps young people realize the importance of the knowledge gained at school, the opportunity to apply it in practice, even expand it in a particular subject, and increases motivation for further learning. King [11] argues that "gap year" is a chance for a schoolboy to a ssert himself as a mature individual, capable of making various decisions, from planning the year itself to putting forward and implementing initiatives, for example, at an internship, which can come in handy at university, where involvement in the learning process is a critical factor for academic performance $[4,11,12]$. According to studies, those applicants who took "gap years" were more successful academically [10] and even young people with low performance in school showed a clear increase in positive results when entering university [7]. According to Coetzee and Bester, this was since after a difficult senior year, exams, gra duates could do something they truly enjoyed [7]. A more relaxed rhythm of life contributes to the graduate's careful thinking about their professional and life goals, building a possible career trajectory.

Recently, some college admissions officers in the United States have adopted a policy that allows enrolled students to defer the start of their studies for one year. Advanced universities (Tufts, Princeton, the University of North Carolina, Florida State University, 
etc.) have seen its positive impact on student motivation and initiative, and on the overall culture of the campus. They have developed and financed programs a imed at students who put off enrollment: they provide them with scholarships to make available to students from different walks of life [13].

The Covid-19 pandemic brought new features to the gap year phenomenon. On the one hand, the lack of opportunities for travel and internships was compensated for by the possibility of taking various online courses, participating in conferences and competitions remotely, or even doing internships remotely. On the other hand, the highest percentage of young people (52\%) living with their parents since the Great Depression was recorded [14], and formany families, it was a lmost impossible to put off enrolling a child for anotheryear due to lack of finances to cover tuition costs [15]. Serious dissatisfaction and unpreparedness to study in a complete distance format also contributed to the rejection of enrollment in 2020 [16]. Quite many Russian school graduates decided to enroll in universities next year, hoping for an improvement in morbidity and financial well-being, the opening of borders for study, and internships abroad [1].

Key characteristics of the gap year are the following: purposeful and practical, in cluding an element of service to others; taking young people out of their comfort zone, encouraging them to develop new skills and explore new perspectives; the right balance of autonomy and mentoring to help youth gain confidence and develop a sense of purpose; and accessibility to people from all economic backgrounds [13].

In general, taking a gap year is an appropriate choice for many young people, although this choice depends largely on the person's socioeconomic situation and the activities in which they are involved during that year[17].

\section{Materials and methods}

The purpose of our study is to analyze the representations of the regional university students about the "gap year" in conditions of the Covid-19 pandemic.

Before conducting the study, we were interested in the following questions:

1. How informed are Russian students about the "gap year" phenomenon and what are their student attitudes toward it?

2. What effect did the COVID-19 pandemic have on the professional plans of 2020 school graduates?

The main research method was a questionnaire developed by the authors. The questions sought to identify students' attitudes toward the "gap year" phenomenon, their opinions on its positives and negatives, and their own experiences of entering the regional university this year.

A total of 208 first-year undergraduate students at the Smolensk State University, aged between 18 and 20 years old (women - 158, men - 42) participated in the study.

\section{Results and Discussion}

\subsection{Questionnaire}

The results of the survey showed that the majority (59.8\%) of respondents did not consider the possibility of postponing enrollment in university until next year. As for the decision to attend university this year, the most common reasons given were: "not wanting to lose a year." (54\%), "parents wanted" (62.2\%), "that's what we did regardless of the pandemic" $(24.3 \%)$, and "not sure that the situation will improve next year" (36.7\%). It is worth noting that the difference of opinions of boys and girls was in significant, but some aspects still 
differed - one of the reasons for not taking an extra year by young people was most often named army service $(72.8 \%)$.

However, those students who did consider postponing enrollment $(40.2 \%)$ noted that they could do so mainly because of low Unified State Exam scores (49.7\%), which made it impossible to enroll in the desired field of study and on budget. Only $12.1 \%$ of respondents stressed that they could take an extra year before admission because of the spread of the pandemic, and, accordingly, restrictions in movement, the inability to study directly within the walls of the chosen university. A small percentage of students $(8.4 \%)$ believe that it is possible to take a yearbreak to rest from studying and difficult state exam inations.

In the case of low scores Unified State Exam, the most correct and acceptable solution was to enter where there are enough scores $(51.9 \%)$, to study where it will be possible, and the next year retake the exams and try to enter the desired university $(40 \%)$, while part of the respondents $(8.1 \%)$ believe that in this case, you must take an extra year to prepare well for the Unified State Exam.

Analysis of the results of the study showed that most students (more than 95\%) have only general ideas about the phenomenon of "gap year" and why they take it. Perhaps such ignorance is primarily because this phenomenon is not so popular in our country, a small number $(7.2 \%)$ have acqua intances with this experience. Respondents noted that taking a $n$ extra year could be useful for those who want to do volunteer work, self-development, travel (42\%), gain work experience (29.6\%), rega in strength to retake exams $(21.5 \%)$ and think calmly and seriously about their professional choices $(6.9 \%)$.

Most respondents said that graduating from high school and going to university in 2020 was not an easy experience. The most difficult for former graduates seemed to be the remote process of applying to university $(34.2 \%)$, the difficulty of taking the Unified State Exam in conditions of tightened security measures $(46.9 \%)$, and the unstable situation in general (47.2\%).

Analysis of the results of the survey showed that more than $72.5 \%$ of respondents do not regret their choice, among them there are those who a re completely satisfied with blended learning at the university or did not even think to take "gap year" in principle. However, at the end of the academic year, about $15 \%$ of first-year students who participated in the study left university for reasons unrelated to academic performance, which may indicate that for them "gap year" could have been useful, but they did not decide to do it immediately because there were no alternative activities or they were afraid to forget the school curriculum during the year, losing the desire to learn. This data is very similar to the results of our previous studies [18].

In addition, students were asked what university they would choose if they decided to enter next year. Most of the respondents (51.2\%) said that they would enter the Smolensk State University anyway, $11 \%$ would go to another Smolensk university, and 36.2\% would try to enter universities in another city.

Thus, the study demonstrated that most students consciously went to university. There was no need for them to interrupt their studies, and they did not consider the possibility to find a vacancy in quarantined conditions or to take an internship in a remote format, which, in our opinion, most Russians do not associate with fundamentality and quality [19]. An analysis of student responses showed that the Covid-19 pandemic had little impact on the professional plans of 2020 school graduates.

\section{Conclusion}

The phenomenon of "gap year" in Russian realities is quite unusual, and due to various reasons (financial instability, service in the army, lack of a clear plan of action during the gap year, etc.) is ill-suited and difficult to implement. The spread of the COVID-19 
pandemic has not had a significant impact on its popularization. In the Russian context, "gap year" is rather presented as "lost-year" - a year of missed opportunities to enter university, time and material expenses, lack of clear benefits, and clearly predictable results.

It seems to us that "gap year" will be more in demand if already at school to inform students about its possibilities. It can also be a positive thing if parents are informed in detail about this phenomenon, as their support is extremely important for the child in this situation. It is necessary to inform the pupils about the possibilities realized during "gap year", about the benefits that they themselves can not only get, but also give during, for example, volunteer activity, about the acquisition of life and professionalexperience.

\section{References}

1. Society and the pandemic: experiences and lessons from the fight aga inst COVID-19 in Russia (2020)

2. M.N. Artemenkov, E.E. Sukhova, Reg. St., 2 (68), 111 (2020)

3. D. Curtis, P. Mlotkowski, M. Lumsden, NCVER (2012)

4. A. Jones, Review of gap yearprovision (2004)

5. K. Simpson, JUD 16, 5 (2004)

6. S. Heath, BJSE 28, 1 (2007)

7. M. Coetzee, S. Bester, SAJHE, 23, 3 (2009)

8. Gap Year Association, https://www.gapyearassociation.org

9. K. Simpson, Antipode, 37, 3 (2005)

10. How Has the Pandemic Affected Your Ability to Afford School?, https://oneclass.com/

11. A. King, JYS, 14,3 (2011)

12. E. Birch, P.W. Miller, TER, 83, 262 (2007)

13. F. Abigail, L. Frey, The Best Freshman Year Is a Gap Year, https://www.chronicle.com/

14. A majority of young adults in the U.S. live with their parents for the first time since the Great Depression, https://www.pewresearch.org/

15. As Colleges Move Classes Online, Families Rebel Against the Cost, https://www.nytimes.com/

16. COVID-19 pandemic leads to approx. $300 \%$ increase in gap years for incoming Penn students, https://www.thedp.com/

17. J. Greenspon, The Gap Year: An Overview of the Issues (2017), http://www.csls.ca/

18. F. Kremen, S. Kremen, IFTE-2020, 1277 (2020)

19. S.A. Kremen, K.P. Tsitsika shvili, INFO'20 communication boundaries, 12, 30 (2020) 